\title{
Estimation of ferrioxamine in jaundiced urine
}

\author{
MICHAEL BARRY AND G. C. CARTEI \\ From the Department of Medicine, The Royal Free Hospital, London
}

SYNOPSIS A simple modification to Fielding and Brunström's method for the estimation of ferrioxamine is described for use with jaundiced urine. Manufactured ferrioxamine HCl may be slightly impure, and when used for standard purposes should be rendered anhydrous and checked for iron content. Standard ferrioxamine solutions suitable for calibrating Fielding and Brunström's method may be prepared by adding standard quantities of ferric iron to excess desferrioxamine.

A rapid and simple spectrophotometric method for the estimation of ferrioxamine in the urine was described by Fielding and Brunström (1964). At $p \mathrm{H} \mathrm{2-4}$ the iron of ferrioxamine rapidly complexes with excess sodium sequestrene to form a colourless ferric salt; the difference in optical density between an appropriately treated aliquot of urine decolourized by sequestrene and an aliquot not exposed to sequestrene is determined and the ferrioxamine concentration obtained by reference to a standard calibration curve for ferrioxamine.

Ferrioxamine has an absorption maximum at $430 \mathrm{~m} \mu$; as the value for bilirubin is similar the presence of bile pigments in urine will seriously interfere with the estimation of ferrioxamine. Simple dilution of the urine has not proved a satisfactory way round this difficulty. Since the measurement of chelated iron in the urine following desferrioxamine administration has important diagnostic and therapeutic applications in liver disease, a simple procedure is reported which renders the most heavily jaundiced urine suitable for ferrioxamine estimation by the method of Fielding and Brunström.

\section{METHOD}

PRINCIPLE Bile pigment is co-precipitated as an insoluble barium complex by the addition of barium chloride to urine. Excess barium is precipitated as barium sulphate (if not removed at this stage the barium will be precipitated by the addition of phosphate buffer during the ferrioxamine estimation). The supernatant solution is then estimated for ferrioxamine by Fielding and Brunström's method.

REAGENTS In addition to the reagents described by Fielding and Brunström the following are prepared from analytical grade chemicals using iron-free, glass-distilled water.

Received for publication 16 June 1967.
Barium chloride $\mathrm{BaCl}_{2} .2 \mathrm{H}_{2} \mathrm{O} 20 \mathrm{~g}$ per $100 \mathrm{ml}$. Sodium sulphate $\mathrm{Na}_{2} \mathrm{SO}_{4} \cdot 10 \mathrm{H}_{2} \mathrm{O} 40 \mathrm{~g}$ per $100 \mathrm{ml}$ The following standard solutions have been used: Stock standard ferric iron solution, $10 \mathrm{mg}$ per $100 \mathrm{ml}$ Ammonium ferric sulphate, $\left(\mathrm{NH}_{4}\right)_{2} \mathrm{SO}_{4} \cdot \mathrm{Fe}_{2}\left(\mathrm{SO}_{4}\right)_{3}, 24 \mathrm{H}_{2} \mathrm{O}$ (MW 964.43), 0.8642 $\mathrm{g}$, is dissolved in water in a $1,000 \mathrm{ml}$ volumetric flask, and $0.5 \mathrm{ml}$ concentrated sulphuric acid added. The solution is made up to the mark with water.

Working standard solutions of ferrioxamine Appropriate aliquots of stock standard ferric iron solution are added to excess desferrioxamine (approximately $250 \mathrm{mg}$ dissolved in $2.5 \mathrm{ml}$ water) in $100 \mathrm{ml}$ volumetric flasks. The solutions are mixed and made up to the mark with water or urine to give standard solutions of desferrioxamine-bound (i.e. ferrioxamine) iron. Concentrations of 500 to $2,500 \mu \mathrm{g}$ iron/100 ml have been convenient; $1,000 \mu \mathrm{g}$ ferrioxamine-iron is equivalent to $11.63 \mathrm{mg}$ ferrioxamine $\mathrm{HCl}$. The formation of ferrioxamine in aqueous solution is associated with a fall in $p \mathrm{H}$, and buffering to $p \mathrm{H} 7$ is necessary to maintain stability of the chelate; $p \mathbf{H}$ adjustment is incorporated in Fielding and Brunström's procedure, however, and unbuffered standards containing a gross excess of desferrioxamine have given the same results by their method as similar standards buffered to $p \mathrm{H} 7$.

PROCEDURE Aliquots of the solution to be estimated, each of $5 \mathrm{ml}$, are pipetted into two disposable plastic tubes (The Metal Box Co. Ltd. Plastics Division, London, S.W.1), and to each is added $1 \mathrm{ml}$ barium chloride. After mixing $1 \mathrm{ml}$ sodium sulphate is added to each tube. The tubes are mixed again and then centrifuged at $\mathbf{3 0 0 0}$ r.p.m. for 10 minutes. A $5 \mathrm{ml}$ aliquot is taken from the supernatant solution of each tube for the estimation of ferrioxamine by the method of Fielding and Brunström. The value is multiplied by 1.4 to correct for the dilution.

\section{RESULTS}

In Fig. 1, ferrioxamine-iron concentration has been 
plotted against extinction. The regression line is shown for standard solutions estimated by Fielding and Brunström's method without initial $\mathbf{B a C l}_{2}$ treatment. The results for solutions prepared in water and normal urine are indistinguishable and have been pooled. Analysis of variance indicates no significant deviation from linearity, a residual error of $E_{430} 0 \cdot 007$, with a regression line slope of $E_{430}$ $0 \cdot 340 / 1000 \mu \mathrm{g}$ ferrioxamine-iron/100 $\mathrm{ml}$ (equivalent to $\mathrm{E}_{430} 0.0292 / \mathrm{mg}$ ferrioxamine $\mathrm{HCl} / 100 \mathrm{ml}$ ).

Similar results were obtained for solutions estimated after $\mathrm{BaCl}_{2}$ treatment. Standards prepared in water, normal urine, and heavily jaundiced urine gave indistinguishable results which have been pooled. After correction for dilution a regression

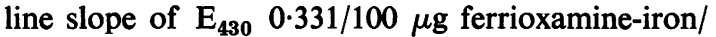
$100 \mathrm{ml}$ is obtained. Comparison of this curve with that obtained for the unmodified procedure indicates $97.5 \%$ mean recovery of ferrioxamine after $\mathrm{BaCl}_{2}$ treatment.

\section{DISCUSSION}

The estimation of ferrioxamine in the urine provides a simple method for monitoring iron excretion during desferrioxamine therapy, in addition to its special application in the differential ferrioxamine test (Fielding, 1965). Both these aspects are relevant in the field of liver disease. The modification described here overcomes the difficulty presented by jaundiced urine without detracting from the simplicity or accuracy of the original method; as the results are in close agreement, the additional steps may be included or omitted as necessary.

Ferrioxamine solutions have been prepared in the manner described owing to the uncertain purity of the ferrioxamine $\mathrm{HCl}$ available for standard purposes. This material, freshly received in the laboratory, has been found to lose $10.7 \%$ weight on vacuum desiccation, and the anhydrous material to have a mean iron content of $7.78 \%$ (range 6.67 $7.94 \%$ ); the theoretical value for iron in ferrioxamine $\mathrm{HCl}$ is $8.59 \%$. A different specimen examined by Mr. P. R. W. Baker of the Wellcome Research Laboratories, Langley Court, Beckenham, Kent, had $8.1 \%$ loss on drying and the anhydrous material $7.95 \%$ iron (by wet ashing with a colorimetric finish using bathophenanthroline, a method similar

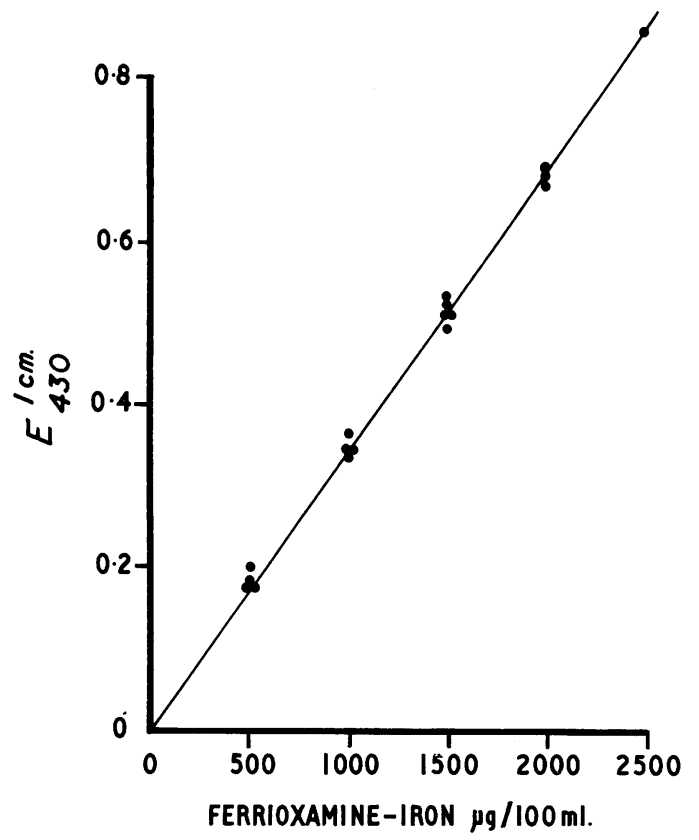

FIG. 1. Calibration curve for ferrioxamine (Fielding and Brunström's method.) Results for 17 standard ferrioxamine solutions prepared from known amounts of iron (1,000 $\mu \mathrm{g}$ ferrioxamine-iron is equivalent to $11.63 \mathrm{mg}$ ferrioxamine $\mathrm{HCl}$ ).

to our own); similar findings have subsequently been made at CIBA Laboratories, Horsham (Burley, 1967). A calibration curve prepared from anhydrous material of this composition would be predicted to give a $7.5 \%$ overestimate of ferrioxamine, whereas the observed overestimate given by such a curve compared with the regression line in Fig. 1 has been $5.5 \%$.

We are grateful to Dr. Barbara Billing for much advice, and to Dr. D. M. Burley of CIBA Laboratories Ltd., Horsham, Sussex, for supplies of ferrioxamine HC1. One of us (M. B.) is in receipt of a Saltwell Fellowship of the Royal College of Physicians, while G. C. received a research grant from the Instituto Patologia Medica, University of Padua.

\section{REFERENCES}

Burley, D. M. (1967). Personal communication. Fielding, J. (1965). J. clin. Path., 18, 88. , and Brunström, G. M. (1964). Ibid., 17, 395. 